\title{
OECD/NRC PSBT Benchmark: Investigating the CATHARE2 Capability to Predict Void Fraction in PWR Fuel Bundle
}

\author{
A. Del Nevo, ${ }^{1}$ D. Rozzia, ${ }^{2}$ F. Moretti, ${ }^{2}$ and F. D'Auria ${ }^{2}$ \\ ${ }^{1}$ ENEA UTIS-TCI, CR Brasimone, 40032 Camugnano, Italy \\ ${ }^{2}$ GRNSPG, University of Pisa, Largo Lucio Lazzarino 2, 56100 Pisa, Italy \\ Correspondence should be addressed to A. Del Nevo, alessandro.delnevo@enea.it
}

Received 7 July 2012; Accepted 21 August 2012

Academic Editor: Maria Avramova

Copyright ( 2012 A. Del Nevo et al. This is an open access article distributed under the Creative Commons Attribution License, which permits unrestricted use, distribution, and reproduction in any medium, provided the original work is properly cited.

\begin{abstract}
Accurate prediction of steam volume fraction and of the boiling crisis (either DNB or dryout) occurrence is a key safety-relevant issue. Decades of experience have been built up both in experimental investigation and code development and qualification; however, there is still a large margin to improve and refine the modelling approaches. The qualification of the traditional methods (system codes) can be further enhanced by validation against high-quality experimental data (e.g., including measurement of local parameters). One of these databases, related to the void fraction measurements, is the pressurized water reactor subchannel and bundle tests (PSBT) conducted by the Nuclear Power Engineering Corporation (NUPEC) in Japan. Selected experiments belonging to this database are used for the OECD/NRC PSBT benchmark. The activity presented in the paper is connected with the improvement of current approaches by comparing system code predictions with measured data on void production in PWRtype fuel bundles. It is aimed at contributing to the validation of the numerical models of CATHARE 2 code, particularly for the prediction of void fraction distribution both at subchannel and bundle scale, for different test bundle configurations and thermalhydraulic conditions, both in steady-state and transient conditions.
\end{abstract}

\section{Introductory Remarks}

A system code shall demonstrate that it is reliable in simulating and predicting the key phenomena of properly selected scenarios. This is a necessary prerequisite for its applicability in accident analysis aimed at demonstrating that a nuclear system is safe and unlikely to fail. The current generation of thermal-hydraulic system (TH-SYS) codes benefits decades of experience in experimental investigation and code development and qualification. They are considered mature tools to provide best estimate description of phenomena and detailed reactor system representation. However, there is still a large margin to improve and refine the modelling approaches taking advantage of more recent techniques that focus on microscopic mechanisms rather than on macroscopic effects, so that more accurate predictions can be obtained and reduction of uncertainties can be achieved. In this view, the qualification of the traditional methods (system codes) can be further enhanced by validation against highquality experimental data (e.g., including measurement of local parameters), while in parallel more sophisticated 3D techniques (such as CFD) are developed and assessed. One of these databases, related to the void fraction measurments, is the pressurized water reactor subchannel and bundle tests (PSBT) conducted by the Nuclear Power Engineering Corporation (NUPEC) in Japan. Selected experiments belonging to this database are used for the OECD/NRC PSBT benchmark.

Prediction of void fraction and DNB in system thermal hydraulics is currently based on empirical approaches. Advancement in understanding and modelling complex flow behaviour in rod bundles would promote the validation of the current approaches and the development of more mechanistic approaches [1].

The aim of the activity is to assess the models of CATHARE2 (six-equation, two-field) code $[2,3]$ by means of void fraction measurements in subchannel configurations and in full scale bundle of Pressurized Water Reactor (PWR) at wide range of thermal-hydraulic boundary conditions (i.e., pressure, power, inlet temperature, and mass flow rate). In particular, the paper presents the results of four subchannel test sections and the analysis of three bundle configurations in steady-state and transient conditions. Sensitivity 

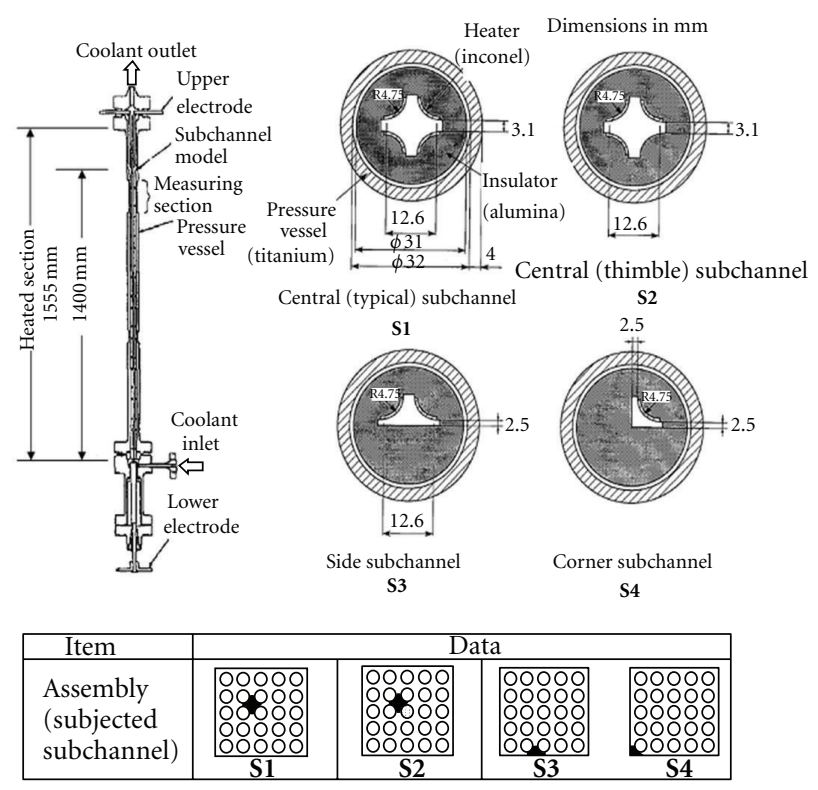

- Subjected subchannel

o Heated rod

o Thimble rod

(a) Test sections for sub-channel void distribution measurement
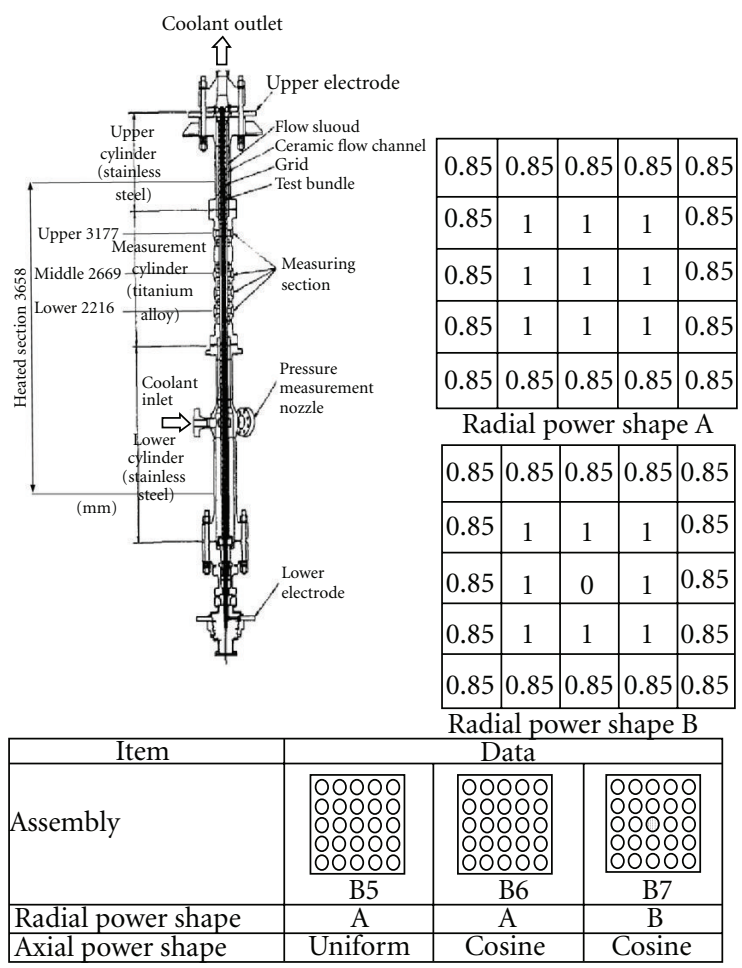

$\circ$ Heated

- Thimble rod

(b) Test sections for rod bundle void measurement

Figure 1: Test sections of PWR subchannel and bundle tests.

analyses are carried out addressing nodalization effect and the influence of the initial and boundary conditions of the tests.

\section{The OECD/NRC NUPEC PSBT Experimental Database}

The pressurized water reactor subchannel and bundle tests were conducted by NUPEC within an extensive experimental campaign aimed at verifying the reliability of fuel assemblies used for commercial nuclear power plants [4]. PSBT is able to simulate the high pressure, high temperature fluid conditions, which are typical of a PWR nuclear power plant (NPP).

The NUPEC test facility (Figure 1) consists of a high pressure and high temperature recirculation loop, a cooling loop, and instrumentation and data recording systems. The recirculation loop consists of a test section, circulation pump, preheater, steam drum (acting as a pressurizer), and a water mixer. The design pressure is $19.2 \mathrm{MPa}$, and the design temperature is $362^{\circ} \mathrm{C}$. The operating conditions of the test facility are shown in Table 1.

The void fraction tests include steady-state subchannel as well as steady-state and transient rod bundle experiments. Four subchannel test assemblies (TS 1, 2, 3, and 4) are used for measuring void fraction, as shown in Figure 1(a). They simulate the subchannel types (central, central with thimble, side, and corner) which are in a PWR assembly. The effective
TABLE 1: Range of NUPEC PWR test facility operating conditions.

\begin{tabular}{lc}
\hline Quantity & Range \\
\hline Pressure & $4.9-16.6 \mathrm{MPa}$ \\
Mass velocity & $550-4150 \mathrm{~kg} / \mathrm{m}^{2} \mathrm{~s}$ \\
Inlet coolant temperature & $140-345^{\circ} \mathrm{C}$ \\
Surface heat flux & $37-186 \mathrm{~W} / \mathrm{cm}^{2}$ \\
\hline
\end{tabular}

heated length is $1555 \mathrm{~mm}$, and the void measurement section begins at $1400 \mathrm{~mm}$ from the bottom of the heated section. The overall subchannel database includes 126 tests, under a wide range of test conditions. Among these, 43 are carried out with TS 1, and TS 2 and 20 using TS 3 and TS 4 (see Figure 1(a)). Complete set of details about geometrical data, boundary conditions of the tests, and experimental results is available in [5].

The rod bundle test sections simulate a partial section and full length of a PWR fuel assembly. Figure 1(b) shows the test section used for the rod bundle void measurements. Three different bundles are used to perform the void distribution measurements (test sections B5, B6, and B7). The effective heated length is $3.618 \mathrm{~m}$. Void fraction measures are available at three different elevations $2.216 \mathrm{~m}, 2.669 \mathrm{~m}$, and $3.177 \mathrm{~m}$, respectively. Steady-state tests were carried out for a wide range of operating conditions. Transient tests were executed increasing the void generation for power increase, 
flow rate reduction, depressurization, and coolant temperature increase. In these tests, thermal-hydraulic conditions comparable with typical scenarios were selected ranging from anticipated transients and postulated accidents. Complete set of details about geometrical data, boundary conditions of the tests, and experimental results is available in [5].

\section{Thermal-Hydraulic Code Nodalizations}

3.1. 1D Models of Subchannel and Bundle Test Sections. Rather simple 1D models were developed for simulating the four subchannel test sections. Here is a summary of the main features of the nodalizations $[6,7]$ :

(i) two BCONDIT components for imposing the boundary conditions of the tests (i.e., pressure, mass flow, and inlet temperature);

(ii) two VOLUME components, which simulate the inlet and the outlet of the test section;

(iii) one AXIAL component, which models the test section.

The electrical heaters of the subchannel and bundle test sections are modelled with WALL components. The linear power is imposed according to the specifications of the tests. The material properties implemented in the nodalization are provided by means of an external FORTRAN subroutine according to the specification in [5].

3.2. 3D Models of Bundle Test Sections. A nodalization of the bundle test section was also developed that takes advantage of the $3 \mathrm{D}$ modelling capabilities of CATHARE2. Here is a summary of the main features of the nodalization:

(i) two BCONDIT components for imposing the boundary conditions of the tests (i.e., pressure, mass flow, and inlet temperature);

(ii) two VOLUME components, which model the inlet and the outlet of the test section, and connected to the THREED component by means of two times 36 junctions;

(iii) a THREED component, having 1296 meshes, which provides a three-dimensional description of the bundle flow. It is discretized according to a Cartesian $6 \times 6$ pattern, so that one "cell" corresponds to one subchannel of the bundle and 36 axial nodes;

(iv) one equivalent heat structure (WALL) is defined for each subchannel;

(v) spacer grids are accounted for by equivalent pressure loss coefficients;

(vi) porosity is set at the junctions and at the volumes to account for the presence of the fuel pins and thus the real hydraulic flow areas;

(vii) turbulence option is activated.

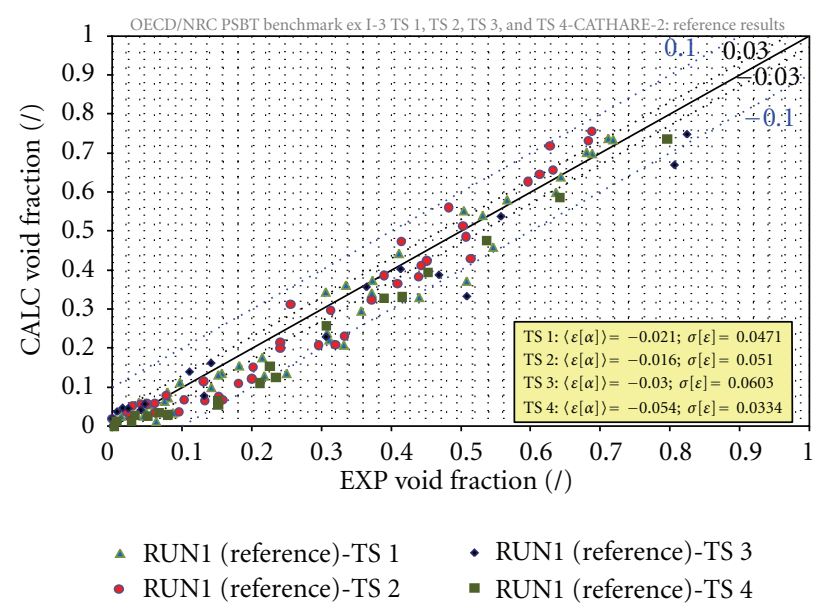

FIGURE 2: Overall subchannels tests (126 tests)—CATHARE2 v2.5_1 code, reference results.

\section{Simulating the PSBT Facility Tests by CATHARE2 Code}

The results of three different types of experiments [8] are discussed hereafter: (1) steady-state subchannel tests; (2) steady-state bundle tests; (3) transient bundle tests. Details of the boundary conditions of the tests are in $[5,8,9]$.

4.1. Posttest Analysis of Steady-State Subchannel Tests. The analysis deals with 126 tests [8] related to the four test sections (see Figure 1(a)). Figure 2 outlines the reference code results (labelled as "RUN1") in simulating the typical central subchannels (including the case with the thimble) and the other two test sections, referred to the side and corner geometries. Different colours are used to distinguish the four test series. Table 2 provides information about the average absolute errors and the corresponding standard deviations for the various tests, grouped by void fraction ranges and by test series.

The results obtained for the 43 tests with Assembly S1 (TS 1 , central subchannel) indicate a systematic underprediction of the void fraction (except at very low and high void fractions). The overall average absolute error on void fraction is -0.021 , while the standard deviation is close to 0.05 . The largest errors (about -0.08) are obtained for void fractions between 0.2 and 0.3 and for higher values of inlet coolant temperature and of system pressure (i.e., greater than $10 \mathrm{MPa})$.

Qualitatively similar results are obtained for Assembly S2 (TS 2, central subchannel with thimble). The same tendency to underprediction of void fraction is shown (except for void fractions below 0.1 and above 0.6 ). The average error is -0.016 , and the standard deviation is 0.051 . Up to void fraction 0.6 , the standard deviation increases with the void fraction.

The results obtained for the 40 tests with Assemblies S3 and $S 4$ (TS 3 and 4, side and corner subchannel) show the same tendencies as for the other tests, but with somewhat larger absolute errors $(-0.03$ and -0.05 , resp.). 
TABLE 2: Summary of subchannels results by CATHARE2 code.

\begin{tabular}{lccccccccccccccc}
\hline $\begin{array}{l}\text { Void } \\
\text { fraction }\end{array}$ & \multicolumn{3}{c}{ TS 1 } & \multicolumn{1}{c}{ TS 2 } & \multicolumn{4}{c}{ TS 3 } & \multicolumn{3}{c}{ TS 4 } & \multicolumn{3}{c}{ Overall } \\
\hline $0.0-0.05$ & 0.005 & 0.0161 & 6 & 0.015 & 0.0092 & 5 & 0.013 & 0.0152 & 8 & -0.004 & 0.0088 & 4 & 0.007 & 0.0143 & 23 \\
$0.05-0.10$ & -0.012 & 0.0244 & 9 & -0.012 & 0.0264 & 6 & - & - & - & -0.040 & 0.0132 & 4 & -0.021 & 0.0251 & 19 \\
$0.10-0.15$ & -0.042 & - & 1 & -0.040 & 0.0262 & 3 & -0.002 & 0.0455 & 3 & - & - & - & -0.028 & 0.0365 & 7 \\
$0.15-0.20$ & -0.023 & 0.0037 & 3 & -0.079 & 0.0080 & 4 & - & - & - & -0.091 & 0.0087 & 2 & -0.064 & 0.0313 & 9 \\
$0.20-0.30$ & -0.081 & 0.0384 & 3 & -0.030 & 0.0533 & 5 & -0.102 & - & 1 & -0.095 & 0.0200 & 3 & -0.077 & 0.0485 & 12 \\
$0.30-0.40-0.038$ & 0.0574 & 8 & -0.057 & 0.0490 & 5 & -0.043 & 0.0496 & 2 & -0.056 & 0.0080 & 2 & -0.048 & 0.0477 & 17 \\
$0.40-0.60-0.032$ & 0.0757 & 7 & -0.009 & 0.0520 & 10 & -0.072 & 0.0759 & 4 & -0.068 & 0.0143 & 3 & -0.045 & 0.0633 & 24 \\
$0.60-0.80$ & 0.007 & 0.0235 & 6 & 0.053 & 0.0267 & 5 & - & - & - & -0.058 & 0.0021 & 2 & 0.000 & 0.0446 & 13 \\
$0.80-1.00$ & - & - & - & - & - & - & -0.107 & 0.0429 & 2 & - & - & - & -0.107 & 0.0429 & 2 \\
\hline
\end{tabular}

The results of the sensitivity calculations (Table 3 ) are summarized in Table 4 and Figure 3. It appears that the average absolute error can be reduced from the reference results as the boundary conditions varied within the uncertainty of the experimental measurements. In particular, the most accurate prediction is achieved using the minimum mass flow rate as boundary condition. However, the dispersion of the results remains similar to that of the reference calculation and the underestimation of void fraction between 0.2 and 0.6 is only slightly improved.

The sensitivity analysis related to the number of axial meshes (RUNS6 and 7) shows some influence on the axial profile of the void fraction. Mesh convergence is already reached with 38 axial subdivisions, as the void fraction axial profile is very close to the more accurate reference solution (RUN 1). The effect is evidenced in Figure 4, where the void fraction of two tests is plotted as a function of height.

4.2. Posttest Analysis of Steady-State Bundle Tests. The experimental data consists of cross-sectional averages of the void fraction measured at three axial locations (bottom, middle, top) along the tests section height. The average, however, is not performed over the entire cross-section but only over the four central subchannels. This has to be taken into account for a proper comparison between numerical results and experimental data. Therefore, the results from the $3 \mathrm{D}$ models (Table 5) are also averaged according to the same procedure for comparison purposes. On the other hand, the results from the 1D models are inherently averaged over the entire cross-section and the comparison with the averaged experimental data would not in principle be appropriate.

The overall database includes 252 steady-state tests, as follows (see Figure 1(b)):

(i) 73 tests of test series 5-Assembly B5 (no thimble; uniform axial power profile),

(ii) 74 tests of test series 6-Assembly B6 (no thimble; cosinusoidal axial power profile),

(iii) 74 tests of test series 7-Assembly B7 (with thimble; cosinusoidal axial power profile),

(iv) 31 tests of test series 8-Assembly B5 (same as TS 5, i.e., no thimble; uniform axial power profile).
The details of the boundary conditions are reported in Table 1 and $[4,5,9]$.

Figure 5 shows a comparison between the results obtained from the 3D model and the measured data, in terms of 4-subchannel cross-sectional averaged void fraction at the three available measurement locations (bottom, centre and top of the test section), for all 73 tests of test series 5 (Assembly B5, with uniform power profile). An annotation in the plot also indicates the absolute accuracy of the experimental data and the absolute error \pm 0.1 in terms of void fraction. Such results indicate that the void fraction is generally overpredicted in the $3 \mathrm{D}$ simulation. The figure includes the results from the $1 \mathrm{D}$ model. The latter are close to the results from 3D model (after averaging over the entire cross-sections), which confirms a consistency between the two models as far as the "integral" performance is concerned. Same qualitative trends, as for TS 5, are observed for the other two test bundles (as described in Figure 1(b)) in Figures 6 and 7 and for the test series 8 using the bundle B5 (Figure 8).

The analysis, based on 252 tests [8], shows generally reasonable (though overestimated) results of the $3 \mathrm{D}$ model (Table 5). Limitations are observed in calculating the average void fraction distribution in the central subchannels. According to the results of the test series 5, 6, and 7, the errors are approximately systematic in terms of absolute average void fraction in the range of $0-0.6$. In particular, the void fraction is overestimated. For higher values $(0.6-0.8)$, the errors are lower, and, in the case of TS 7, the code void fraction is largely underestimated. These results highlight that the cross flows from the inner towards the outer subchannels of the $3 \mathrm{D}$ model are underestimated by the code, until the void fraction is below 0.6 .

The test cases with cosine power profile showed higher absolute errors than the uniform axial power profile tests. The code results of TS 8 evidence a good average accuracy. The results are centred across the experimental data and better than those of TS 5 . It has to be remarked that TS 5 and TS 8 share the same geometrical configuration, and no difference is reported in the PSBT benchmark specifications. The comparisons with the $1 \mathrm{D}$ results highlight that the void fraction, in general, keeps being overestimated in subcooled 
TABLE 3: PSBT subchannel tests: list of reference and sensitivity calculations.

\begin{tabular}{lccccc}
\hline Test section & ID & Number of axial nodes & Pressure (1) & Mass flow (1) & Note \\
\hline & RUN1 & 100 & Nominal & Nominal & Reference \\
& RUN2 & 100 & Nominal & Minimum & - \\
& RUN3 & 100 & Nominal & Maximum & - \\
Steady-state subchannel & RUN4 & 100 & Minimum & Maximum & - \\
& RUN5 & 100 & Maximum & Nominal & - \\
& RUN6 & 38 & Nominal & Nominal & Effect of pressure drop \\
& RUN7 & 16 & Nominal & Nominal & CATHARE3 (2) (same results are RUN1) \\
& C3 & 100 & Nominal & Nominal & CATHare
\end{tabular}

(1) Nominal: as specified in [5]. Minimum and maximum: according to the estimated accuracy of the measurement system.

(2) CATHARE3 is the new two-phase thermal-hydraulics system code developed at CEA to expand the capabilities of CATHARE2 (e.g., three field model, and turbulence transport for a continuous field or interfacial area transport for a dispersed field). CATHARE3 was applied against the PSBT data using the standard 6-equation model of CATHARE2. Thus, the task was a verification and a nonregression activity. The results are not reported here for sake of simplicity.

TABLE 4: PSBT subchannel tests, CATHARE2: summary of sensitivity analysis results.

\begin{tabular}{lccccccccccccc}
\hline \multirow{2}{*}{ Void fraction } & \multicolumn{3}{c}{ TS 1 } & \multicolumn{3}{c}{ TS 2 } & \multicolumn{3}{c}{ TS 3 } & \multicolumn{3}{c}{ TS 4 } \\
& $\langle\varepsilon[\alpha]\rangle$ & $\sigma[\varepsilon]$ & Number & $\langle\varepsilon[\alpha]\rangle$ & $\sigma[\varepsilon]$ & Number & $\langle\varepsilon[\alpha]\rangle$ & $\sigma[\varepsilon]$ & Number & $\langle\varepsilon[\alpha]\rangle$ & $\sigma[\varepsilon]$ & Number \\
\hline RUN1 (refrence) & $-\mathbf{0 . 0 2 1}$ & $\mathbf{0 . 0 4 7 1}$ & $\mathbf{4 3}$ & $-\mathbf{0 . 0 1 6}$ & $\mathbf{0 . 0 5 1 0}$ & $\mathbf{4 3}$ & $-\mathbf{0 . 0 3 0}$ & $\mathbf{0 . 0 6 0 3}$ & $\mathbf{2 0}$ & $-\mathbf{0 . 0 5 4}$ & $\mathbf{0 . 0 3 3 4}$ & $\mathbf{2 0}$ \\
RUN2 & -0.006 & 0.0489 & 43 & -0.005 & 0.0493 & 43 & -0.018 & 0.0617 & 20 & 0.044 & 0.0281 & 20 \\
RUN3 & -0.036 & 0.0474 & 43 & -0.027 & 0.0537 & 43 & -0.041 & 0.0610 & 20 & -0.063 & 0.0402 & 20 \\
RUN4 & -0.010 & 0.0434 & 43 & -0.006 & 0.0472 & 43 & -0.019 & 0.0577 & 20 & -0.043 & 0.0279 & 20 \\
RUN5 & -0.032 & 0.0512 & 43 & -0.029 & 0.0534 & 43 & -0.040 & 0.0637 & 20 & -0.063 & 0.0391 & 20 \\
RUN6 & -0.018 & 0.0475 & 43 & -0.014 & 0.0503 & 43 & -0.028 & 0.0606 & 20 & -0.052 & 0.0321 & 20 \\
RUN7 & -0.005 & 0.0500 & 43 & -0.004 & 0.0488 & 43 & -0.017 & 0.0622 & 20 & -0.044 & 0.0276 & 20 \\
\hline
\end{tabular}

boiling conditions. The activation of the turbulence model improves the accuracy of the results; nevertheless, it should be considered that it has not been developed for such kind of applications [8].

4.3. Posttest Analysis of Transient Bundle Tests. The behaviour of three bundle test sections (i.e., B5, B6, and B7) are simulated in transient conditions (i.e., power increase, pressure decrease, flow decrease, and coolant inlet temperature increase). The analysis deals with 12 transient tests [8] modelled with the 3D and 1D nodalizations (see Section 3). Hereafter the results of three out of twelve tests are reported for sake of simplicity (the overall results are available in [8]). They are (1) a flow reduction test with the bundle B5; (2) the coolant temperature at inlet increase test with the bundle B6; (3) the power increase test with the bundle B7.

The flow reduction test with the bundle B5 is characterized by the following constant boundary conditions: electrical power equal to $2250 \mathrm{~kW}$, system pressure $15.1 \mathrm{MPa}$, coolant temperature at the inlet $302^{\circ} \mathrm{C}$ (subcooling $41^{\circ} \mathrm{C}$ ). The experimental and calculated mass flow rate trends are reported in Figures 9(a) and 9(b) that show the time histories of both the calculated and the measured averaged void fractions for the three different measuring locations (as already discussed for the steady-state tests in Section 4.2). During the steady-state period that comes before the flow rate variation (reduction), a noticeable void fraction is predicted by the code at the upper location, while the measured value in the experiment is practically zero. This evidence is consistent with the results for steady-state tests, which also showed a general tendency to overpredict the void fraction in the central channels. On the other hand, the transient trends are rather well predicted, with a certain tendency to under estimation.

The coolant temperature increase test with the bundle B6 is performed at a system pressure of $15.4 \mathrm{MPa}$, electrical power equal to $2600 \mathrm{~kW}$, and a constant mass flow rate of $8 \mathrm{~kg} / \mathrm{s}$. The coolant temperatures at inlet of the bundle have the trend reported in Figure 10(a), with a subcooling ranging from $49^{\circ} \mathrm{C}$ to $16^{\circ} \mathrm{C}$. Figure 10 (b) reports both the calculated and the measured averaged void fractions, for the three different measuring locations. The void fraction predicted at the top and middle locations before the beginning of the temperature rise is above the measured value. The increase in void fraction during the transient is predicted quite in advance and with smoother rates compared to the experiment. This is also connected with the position where the coolant temperature is measured: the thermocouple is upstream the test section. On the contrary, the boundary conditions in the calculation are set just below the fuel bundle. The maximum values of the predicted void fraction are comparable with the measured ones.

The power increase test with the bundle B7 has the following boundary conditions: the system pressure is equal to $15.5 \mathrm{MPa}$, the coolant temperature inlet is $288^{\circ} \mathrm{C}$, corresponding to a subcooling of $57^{\circ} \mathrm{C}$, and the mass flow rate is set to $8 \mathrm{~kg} / \mathrm{s}$. Figures $11(\mathrm{a})$ and $11(\mathrm{~b})$ show the time histories of both the calculated and the measured bundle powers and averaged void fractions, for the three different measuring 
TABLE 5: PSBT steady-state bundles (TS 5, TS 6, TS 7, TS 8,): summary of reference calculations results by CATHARE2 3D model.

\begin{tabular}{lcccccccccccccc}
\hline \multirow{2}{*}{ Void fraction } & \multicolumn{3}{c}{ TS 5 } & \multicolumn{3}{c}{ TS 6 } & \multicolumn{3}{c}{ TS 7 } & \multicolumn{3}{c}{ TS 8 } \\
& $\langle\varepsilon[\alpha]\rangle$ & $\sigma[\varepsilon]$ & Number & $\langle\varepsilon[\alpha]\rangle$ & $\sigma[\varepsilon]$ & Number & $\langle\varepsilon[\alpha]\rangle$ & $\sigma[\varepsilon]$ & Number & $\langle\varepsilon[\alpha]\rangle$ & $\sigma[\varepsilon]$ & Number \\
\hline $0.0-0.05$ & 0.1003 & 0.0448 & 54 & 0.0931 & 0.0351 & 53 & 0.1031 & 0.0468 & 53 & 0.0469 & 0.0290 & 17 \\
$0.05-0.10$ & 0.0895 & 0.0396 & 21 & 0.1074 & 0.0295 & 21 & 0.1068 & 0.0491 & 21 & 0.0425 & 0.0606 & 3 \\
$0.10-0.15$ & 0.1017 & 0.0644 & 15 & 0.1511 & 0.0785 & 19 & 0.1310 & 0.0718 & 19 & 0.0102 & 0.0514 & 4 \\
$0.15-0.20$ & 0.0801 & 0.0615 & 15 & 0.1408 & 0.0836 & 11 & 0.1323 & 0.0778 & 11 & 0.0392 & 0.0675 & 7 \\
$0.20-0.30$ & 0.0464 & 0.0639 & 26 & 0.0951 & 0.0567 & 21 & 0.1134 & 0.0598 & 21 & -0.0333 & 0.0783 \\
$0.30-0.40$ & 0.0335 & 0.0568 & 27 & 0.0827 & 0.0541 & 33 & 0.1050 & 0.0741 & 33 & -0.0344 & 0.0741 \\
$0.40-0.60$ & 0.0827 & 0.0612 & 48 & 0.0946 & 0.0694 & 47 & 0.0603 & 0.0514 & 47 & 0.0144 & 0.0771 & 25 \\
$0.60-0.80$ & 0.0256 & 0.0388 & 13 & 0.0253 & 0.0555 & 17 & -0.0908 & 0.0796 & 17 & 0.0310 & 0.0285 & 8 \\
$0.80-1.00$ & - & - & 0 & - & - & 0 & -0.2784 & - & 0 & - & - & 0 \\
\hline $0.0-1.00$ (total) & 0.061 & 0.0599 & 219 & 0.091 & 0.0651 & 222 & 0.082 & 0.0939 & 222 & 0.014 & 0.0675 & 93 \\
\hline
\end{tabular}

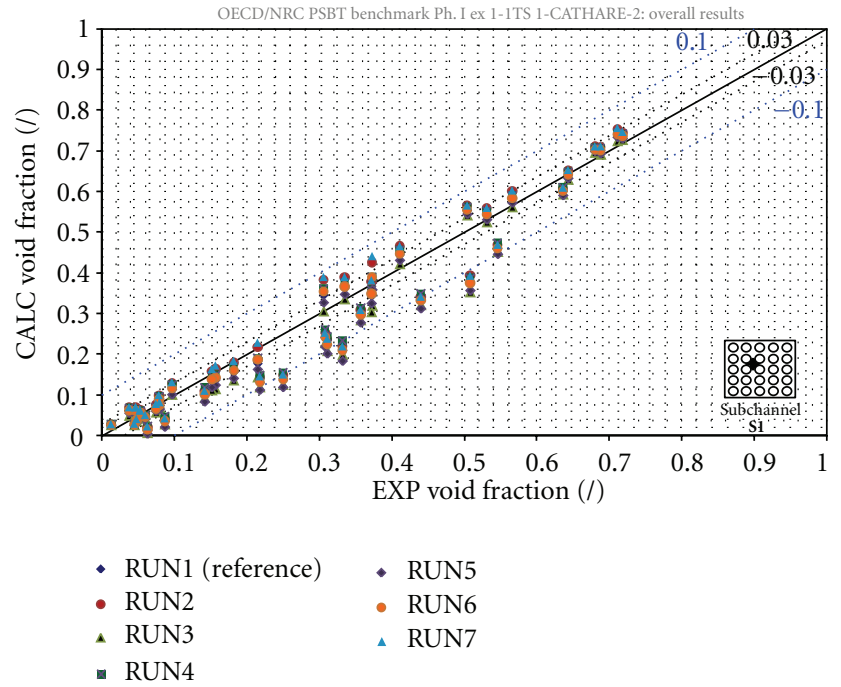

(a) Test Series 1

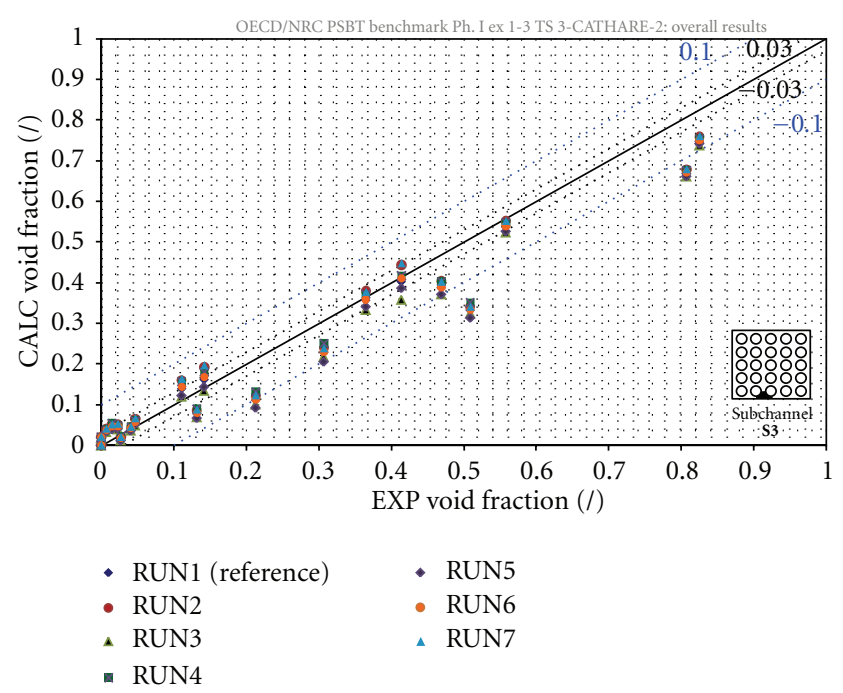

(c) Test Series 3

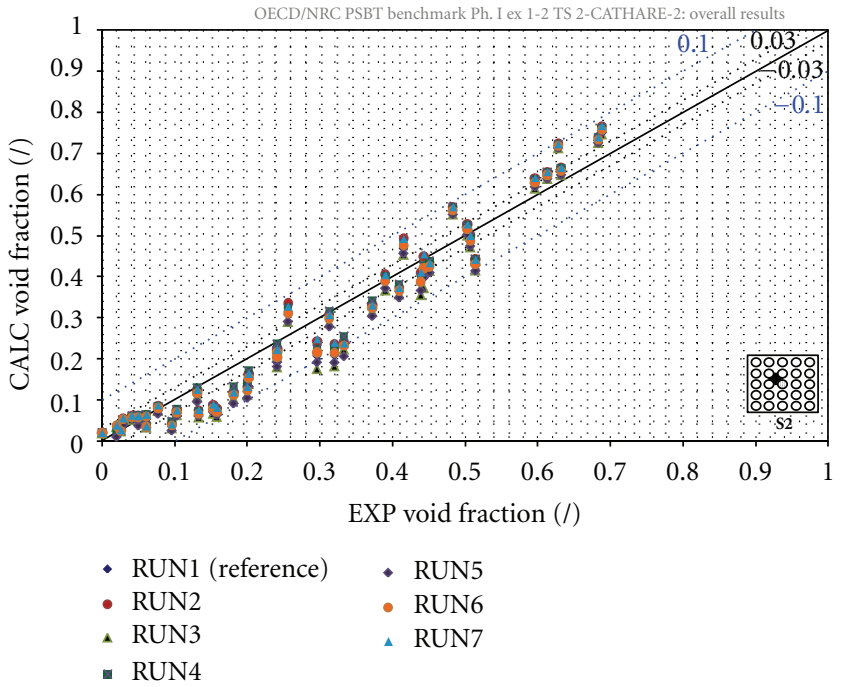

(b) Test Series 2

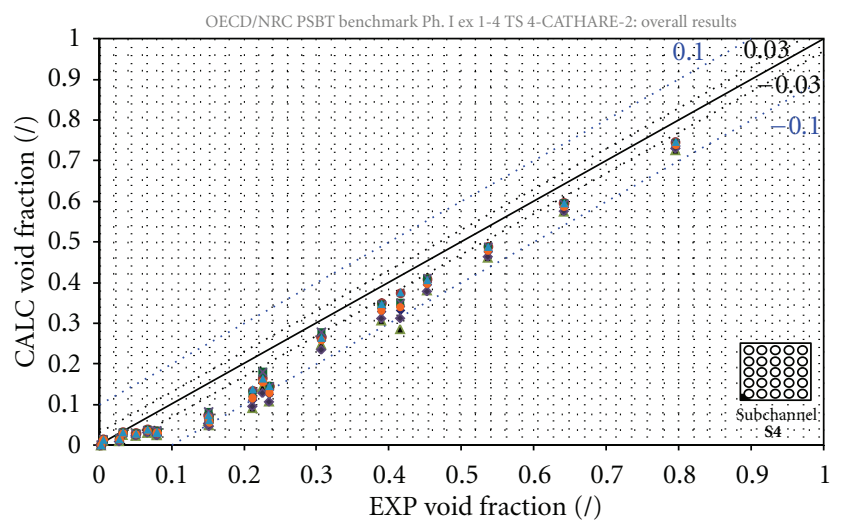

$\begin{array}{ll}\text { - RUN1 (reference) } & \text { - RUN5 } \\ \text { - RUN2 } & \text { - RUN6 } \\ \text { - RUN3 } & \text { × RUN7 } \\ \text { - RUN4 } & \end{array}$

(d) Test Series 4

FIgURE 3: Overall subchannels tests (126 tests)—sensitivity calculations. 


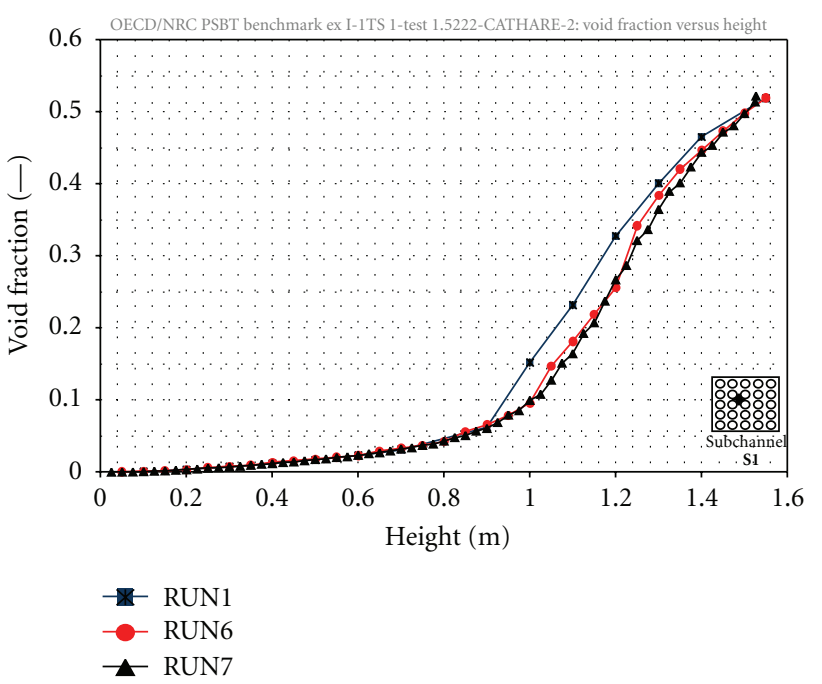

(a) Test 1.5222

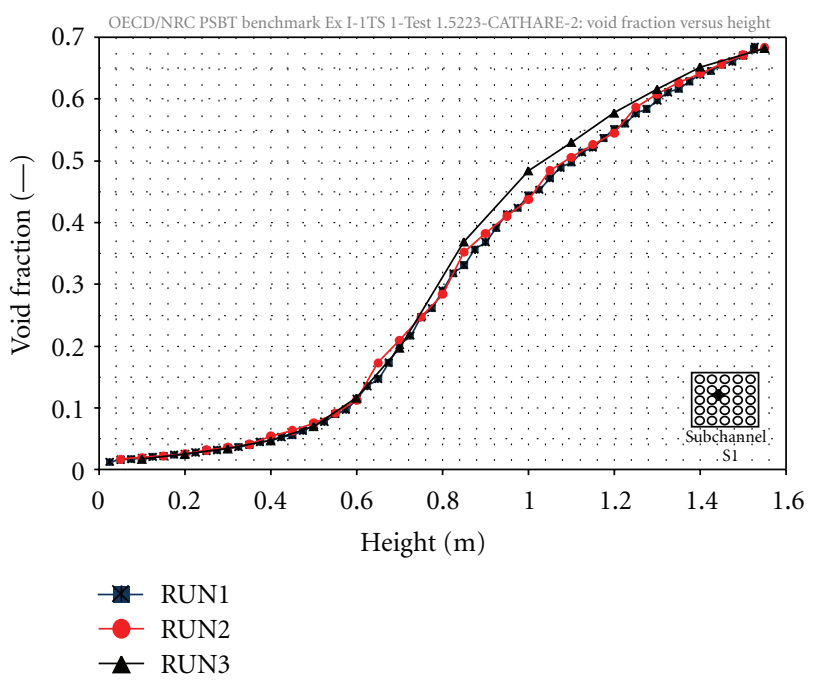

(b) Test 1. 5223

Figure 4: Test Series 1 (tests 1.5222 and 1.5223)—CATHARE2 code, nodalization effect.

locations. At the top location, the increase in void fraction during the transient is predicted with a certain delay compared to the experiment (except for an earlier "disturbance"); then the calculated void fraction trend stabilizes at the same level as the measured one. On the other hand, the void fraction is noticeably overpredicted at the middle and bottom locations.

In general, the code assessment of CATHARE2 code against the PSBT transient bundle tests demonstrates satisfactory results obtained by the 3D model. In particular,

(i) a noticeable void fraction is predicted by the code at the upper location (and middle location in the temperature increase test, Figure 10), while the measured value is practically zero. This is consistent with the results observed in the steady-state tests;

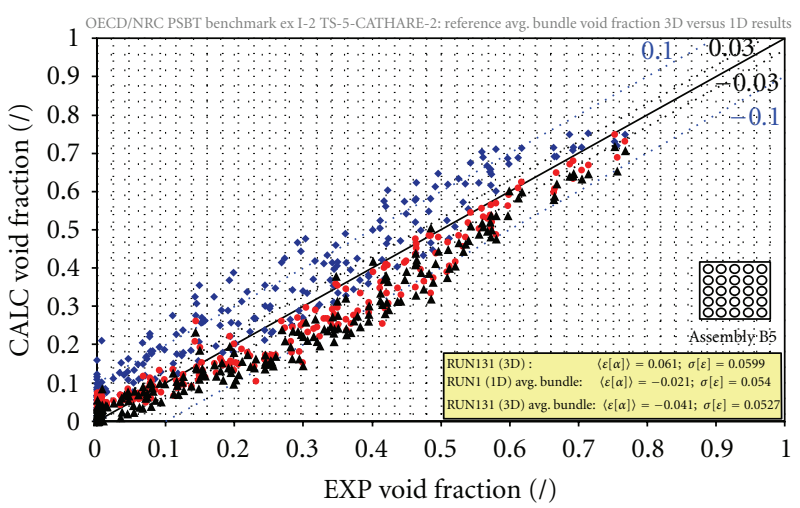

- Avg. central void fraction-RUN 131 (3D)

- Avg. bundle void fraction-RUN 1 (1D reference)

- Avg. bundle void fraction-RUN 131 (3D)

Figure 5: PSBT steady-state bundle (TS 5) —CATHARE2 3D and 1D models: central and bundle void fraction exp. versus calc., reference results.

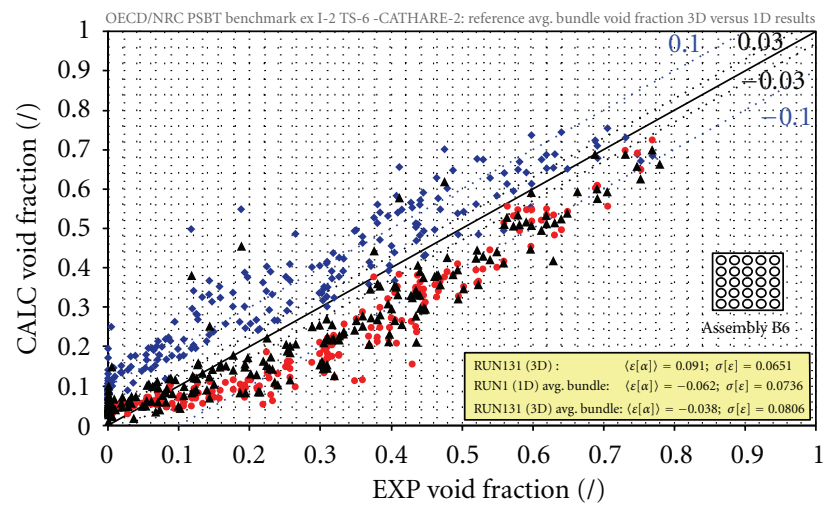

- Avg. central void fraction-RUN 131 (3D)

- Avg. bundle void fraction-RUN 1 (1D reference)

- Avg. bundle void fraction-RUN 131 (3D)

Figure 6: PSBT steady-state bundle (TS 6) -CATHARE2 3D and 1D models: central and bundle void fraction exp. versus calc., reference results.

(ii) good prediction of the maximum void fraction is in general calculated: exceptions are the few disturbances observed at the start of the transients.

\section{Conclusive Remarks}

This work dealt with the validation of CATHARE2 capabilities in predicting void fraction in convective boiling flows. The validation is performed using the experimental data from NUPEC, also involved in the OECD/NRC PSBT benchmark. Four subchannel and three bundle test sections are simulated in different thermal-hydraulic conditions (i.e., pressure, coolant temperature, mass flow, and power). The overall database includes steady-state and transient tests (i.e., pressure decrease, power increase, coolant inlet temperature increase, and mass flow rate decrease). Sensitivity analyses 


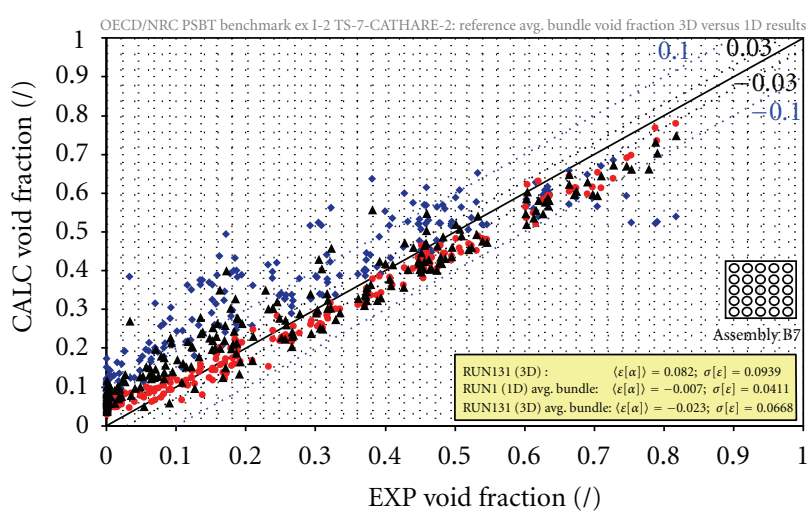

- Avg. central void fraction-RUN 131 (3D)

- Avg. bundle void fraction-RUN1 (1D reference)

- Avg. bundle void fraction-RUN 131 (3D)

Figure 7: PSBT steady-state bundle (TS 7)_CATHARE2 3D and 1D models: central and bundle void fraction exp. versus calc., reference results.

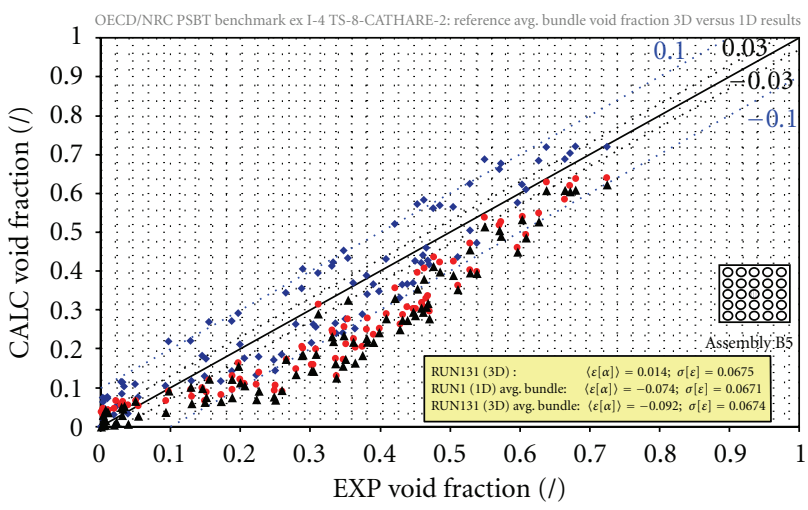

- Avg. central void fraction-RUN 131 (3D)

- Avg. bundle void fraction-RUN1 (1D reference)

- Avg. bundle void fraction-RUN 131 (3D)

FIgURE 8: PSBT steady-state bundle (TS 8)-CATHARE2 3D and 1D models: central and bundle void fraction exp. versus calc., reference results.

are carried out, which investigate the influence of number of nodes, different code option, initial and boundary conditions of the tests on the code predictions.

The analysis of 126 steady-state subchannel tests shows reasonable results for lower values of void fraction; underprediction for intermediate values of void fraction (i.e., $0.2-0.4$ ) and good results for higher values.

(i) The void fraction is overestimated in subcooled boiling conditions. The opposite is observed in saturated boiling conditions (bubbly, slug, and churn flow regimes).

(ii) The sensitivity analysis demonstrates that the prediction can be improved by varying the boundary conditions of the simulations inside the range of their uncertainty.

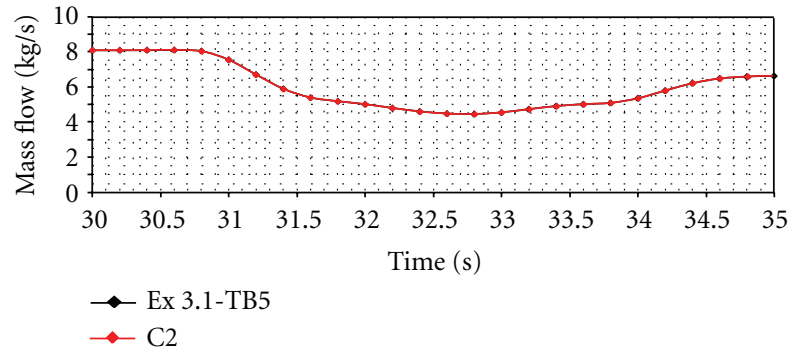

(a) mass flow rate versus time

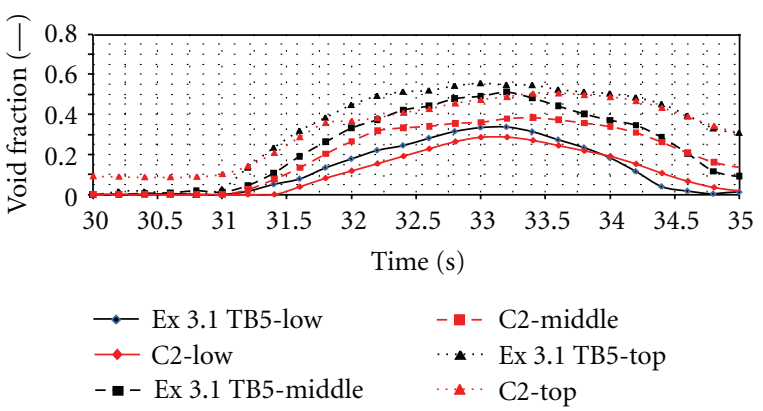

(b) void fraction versus time

FIGURE 9: PSBT transient bundle tests (TS 5) -flow reductionCATHARE2 3D: calc. versus exp., reference results (RUN131).

(iii) The sensitivities addressing the effect of the number of nodes show the convergence of the mesh for number of nodes larger than 38 .

The analysis of 252 steady-state bundle tests evidenced conservative (overestimated) results of the 3D model. In particular,

(i) limitations are observed in calculating the average void fraction distribution in the central subchannels (i.e., void dispersion connected with the cross flow). The errors are approximately systematic in terms of absolute average void fraction in the range of 0-0.6. In particular, the void fraction is overestimated. For higher values $(0.6-0.8)$, the errors are lower, and, in the case of TS 7, the code void fraction is largely underestimated;

(ii) the test cases with cosine power profile showed higher absolute errors than the uniform axial power profile tests;

(iii) the code results of TS 8 evidence a good average accuracy. The results are centred across the experimental data. They are better than those of TS 5, which has the same geometrical configuration;

(iv) the comparisons with the $1 \mathrm{D}$ results confirm that the void fraction is, in general, overestimated in subcooled boiling conditions;

(v) the activation of the turbulence model improves the accuracy results. Nevertheless it should be considered that this option is not developed for such kind of applications. 


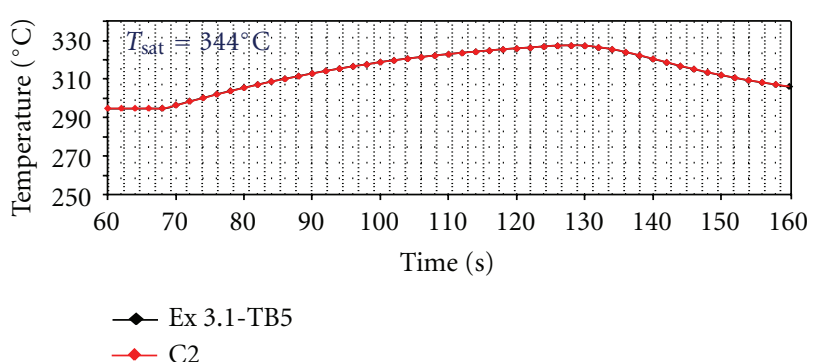

(a) coolant temperature at core inlet

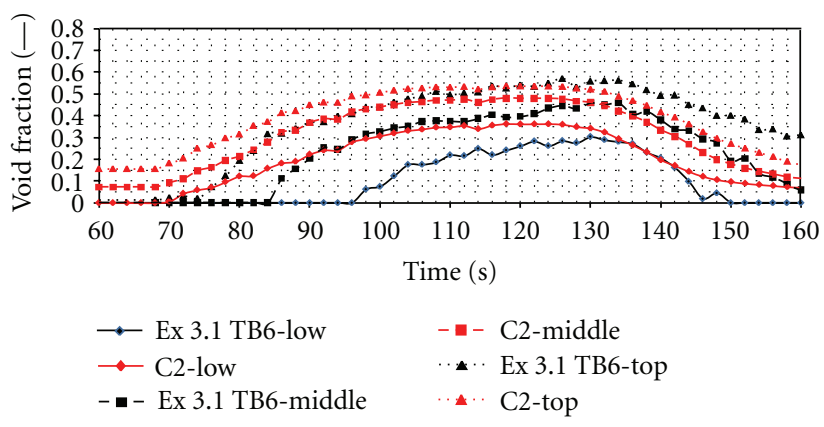

(b) void fraction versus time

FIGURE 10: PSBT transient bundle tests (TS 6)—-temperature increase-CATHARE2 3D: calc. versus exp., reference results (RUN131).

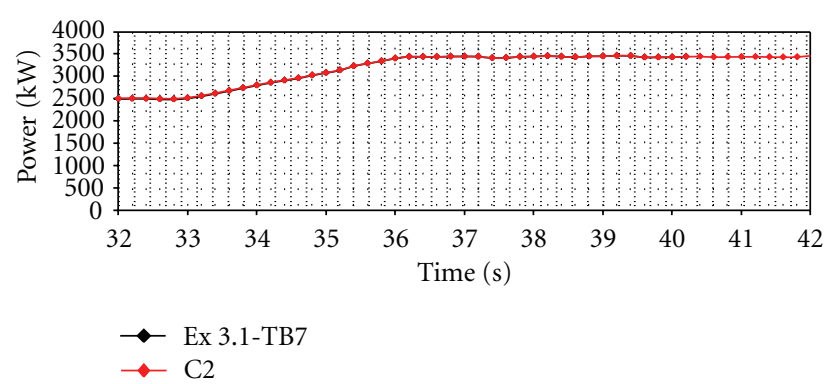

(a) Power versus time

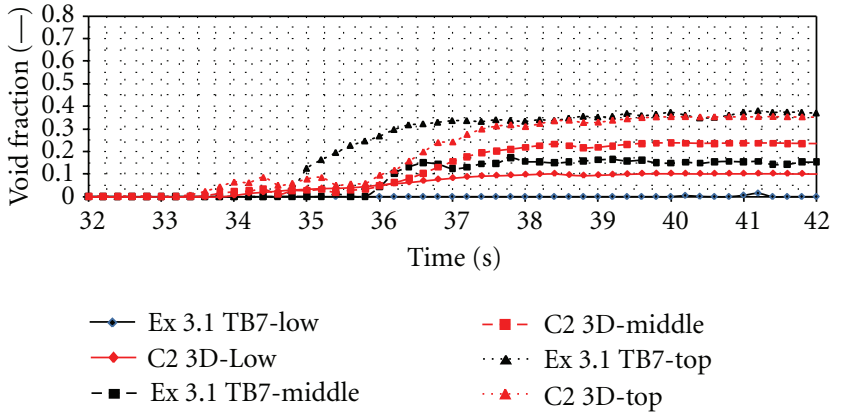

(b) void fraction versus time

FIGURE 11: PSBT transient bundle tests (TS 7)—power increase-CATHARE2 3D: calc. versus exp., reference results (RUN131).

The analysis of 12 transient bundle tests shows satisfactory results of the 3D model. In particular:

(i) A noticeable void fraction is predicted by the code at the upper location, while the measured value is practically zero. This is consistent with the results observed in the steady-state tests.

(ii) Good prediction of the maximum void fraction is in general calculated.

\section{Nomenclature}

$\begin{array}{ll}\alpha: & \text { Void fraction } \\ \varepsilon: & \text { Average value } \\ \sigma: & \text { Standard deviation } \\ \text { 1D: } & 1 \text { dimensional } \\ \text { 3D: } & 3 \text { dimensional }\end{array}$

CATHARE2: Code for analysis of thermal-hydraulics during an accident of reactor and safety evaluation

CFD: $\quad$ Computational fluid dynamic

DNB: $\quad$ Departure from nucleate boiling

ENEA: Agenzia nazionale per le nuove tecnologie, l'energia e lo sviluppo economico sostenibile

OECD: Organization for Economic Co-operation and Development

NEA: $\quad$ Nuclear Energy Agency
NPP: Nuclear power plant

NRC: Nuclear Regulatory Commission

NUPEC: Nuclear Power Engineering Corporation

PSBT: Pressurized water reactor subchannel and bundle tests

PWR: Pressurized water reactor

TB: $\quad$ Test bundle

TS: $\quad$ Test series

UNIPI: Università di Pisa.

\section{Acknowledgments}

The authors would like to acknowledge the OECD Nuclear Energy Agency (NEA) and the NRC that promoted the PSBT benchmark and the CATHARE Team (in particular, M. Valette and D. Bestion) for the kind and valuable technical support.

\section{References}

[1] B. Niceno, M. Andreani, B. L. Smith et al., "Program of Work for Development and Validation for LOCA," in Proceedings of the 7th EURATOM FP, 2008-2012 Collaborative Project: NURISP, SP 2: Thermal Hydraulics, Task D2. 4. 1, 2009.

[2] G. Lavialle, CATHARE2 V2. 5 User Guidelines, SSTH/LDAS/ EM/2004-067, CEA, Grenoble, France, 2005.

[3] C. Eymard, CATHARE2 V2. 5 User Manual, SSTH/LDAS/EM/ 2004-040, CEA, Grenoble, France, 2005. 
[4] K. Hori, K. Miyazaki, T. Kurosu, S. Sugiyama, J. Matsumoto, and Y. Akiyama, "In bundle void fraction measurement of PWR fuel assembly," in Proceedings of the 2nd ASME-JSME Nuclear Engineering Joint Conference, pp. 69-76, March 1993.

[5] A. Rubin, M. Avramova, and H. Utsuno, "OECD/NRC benchmark based on NUPEC PWR Subchannel and Bundle Tests (PSBT)," in Proceedings of the International Conference on the Physics of Reactors (PHYSOR '10), pp. 2723-2732, May 2010.

[6] L. Michelotti, A. Del Nevo, D. Rozzia, and F. D'Auria, "Prediction of void fraction in PWR sub-channel by CATHARE 2 Code," in Proceedings of the International Conference on Acoustics, Speech and Signal Processing (ICAPP '11), Nice, France, May 2011, Paper 11396.

[7] A. Del Nevo, L. Michelotti, D. Rozzia, F. Moretti, and F. D’Auria, "Void fraction prediction of NUPEC PSBT Tests by CATHARE code," in Proceedings of the NURETH-14, Ontario, Canada, September 2011, paper 415.

[8] A. Del Nevo, F. Moretti, D. Rozzia, and F. D'Auria, "Final report on modeling and validation of multi-field models, dynamic interfacial area and turbulence for LOCA conditions," EC FP7 NURISP Project D-2. 4. 2. 10b Rev. 1, 2012.

[9] JNES, "OECD/NEA Benchmark Based on NUPEC PWR Subchannel and Bundle Tests (PSBT). Assembly specification and benchmark database (Volume 1)," Japan Nuclear Energy Safety Organization (JNES) SAE-TH08-0019, 2009. 

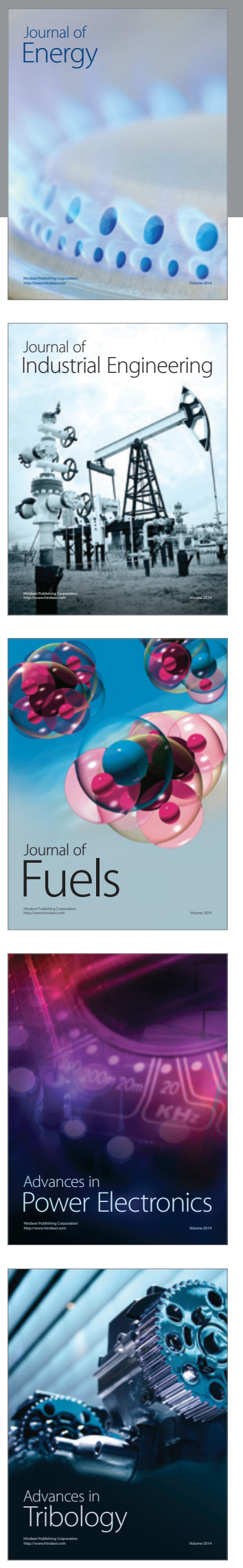
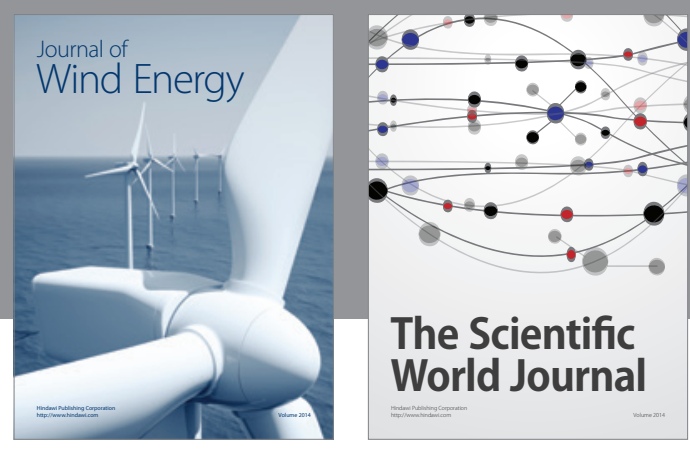

The Scientific World Journal

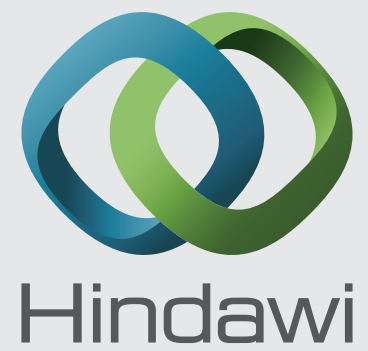

Submit your manuscripts at http://www.hindawi.com
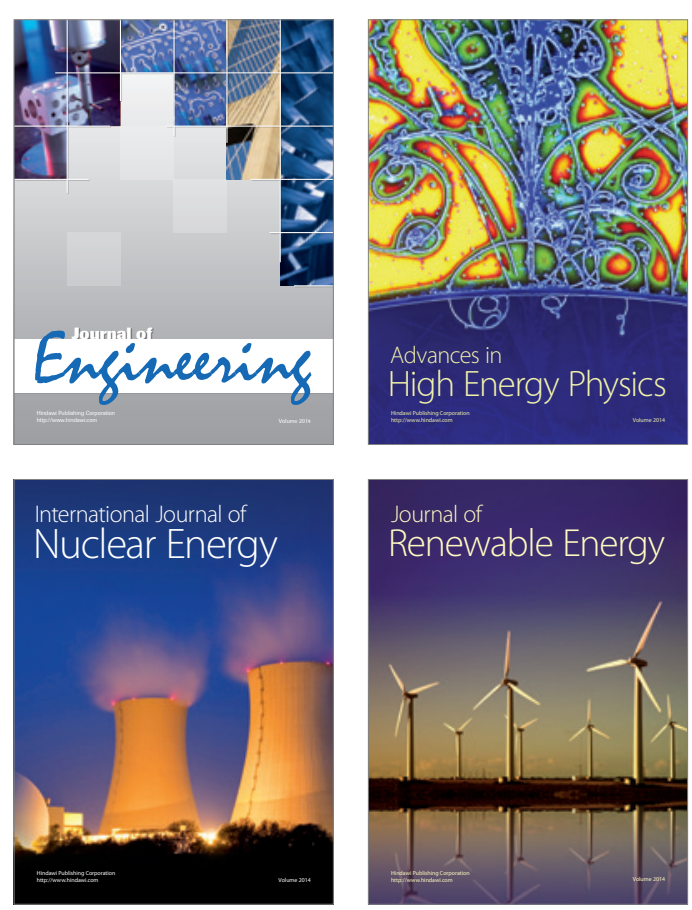

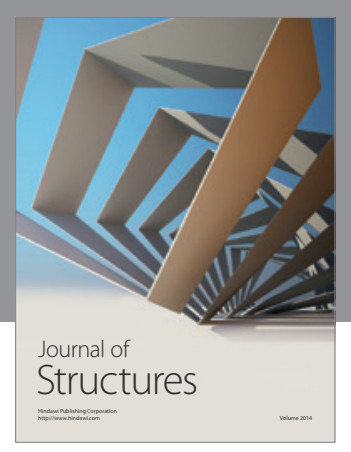

Rotating
Mechinery
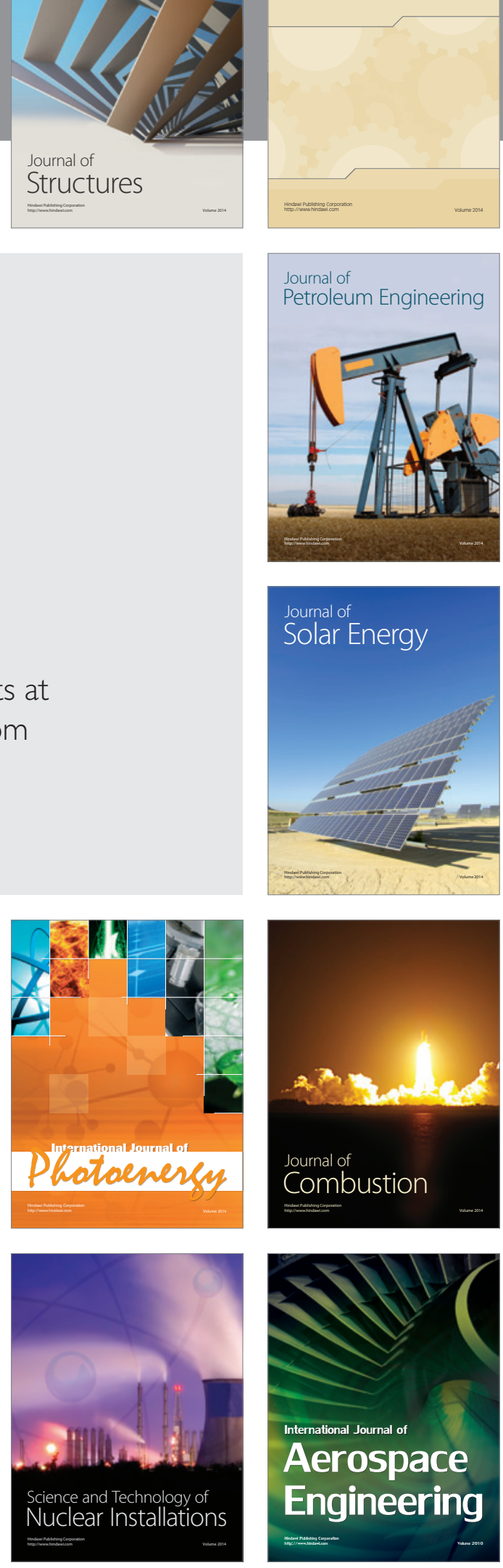